\title{
Viver a (e para) aprender: uma intervenção-ação para a promoção do envelhecimento ativo
}

\author{
Live (and) to learn: an intervention for the active aging promotion
}

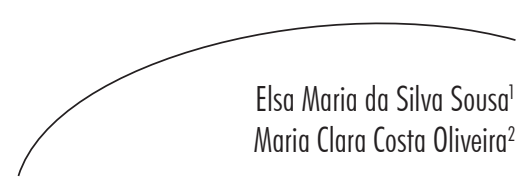

\section{Resumo}

A intervenção aqui descrita teve como objetivo contribuir para o envelhecimento ativo de usuários de centros-dia/convívio para idosos, desenvolvendo harmoniosamente todas suas dimensões, visando que os utentes fossem autônomos, participativos e ativos. Recorrendo ao paradigma interpretativo-hermenêutico, apoiamo-nos num trabalho de investigação-ação participativa, construído e implementado em dois centros-dia/ convívio do conselho da Póvoa de Lanhoso, distrito de Braga, Portugal, e que contou com um total de 25 usuários: 12 no centro de convívio A e 13 no centro de convívio $B$. O objetivo foi transversal a todas as atividades implementadas, tendo sido alcançado como revelam os resultados satisfatórios obtidos na avaliação da intervenção (e de cada uma das atividades). A avaliação contínua e final permitiu, igualmente, aferir que todas as atividades desenvolvidas foram do agrado dos usuários e que todas lhes possibilitaram novos conhecimentos que os ajudaram na sua vida diária, aumentando, consequentemente, sua qualidade de vida e tornando-os mais autônomos, participativos e ativos.

\section{Abstract}

The intervention here described aimed to contribute to the harmonious development of senior users of day centers in all their personal dimensions so that they become autonomous, participative and active. Using interpretative-hermeneutic paradigm, we rely on a participatory action research, built and implemented in two day centers in the county of Póvoa de Lanhoso, district of Braga, Portugal, which had a total of 25 users: 12 in the social center A and 13 in the social center B. That objective crossed all the implemented activities and was achieved as shown by the good results obtained in the evaluation of the intervention (and each activity). Continuous and final evaluation provided also check that all activities carried out were liked by the persons; they also allowed to demonstrate that those persons produced new knowledge that helped them in their daily lives, increasing therefore their quality of life and making them more autonomous, participative and active.

\footnotetext{
Universidade do Minho, Instituto de Educação. Braga - Portugal.

2 Universidade do Minho, Instituto de Educação, Centro de Estudos Humanísticos. Braga - Portugal.
}

Palavras-chave:

Envelhecimento.

Envelhecimento Ativo.

Aprendizagem ao Longo

da Vida.

Key words: Aging. Active Aging. Lifelong Learning and Education. 


\section{INTRODUÇÃO}

O envelhecimento é uma realidade predominante em Portugal e tema bastante preocupante. Embora já se observem progressos neste âmbito, muito ainda há por fazer.

Em Portugal, segundo o Instituto Nacional de Estatística, a partir dos censos realizados em 2011, a população idosa com mais de 65 anos de idade residente é de 2,023 milhões de pessoas, representando cerca de $19 \%$ da população total. ${ }^{1}$ Pode-se ainda corroborar, por meio dos censos realizados em 2011, que a distribuição da população com 65 ou mais anos apresenta padrão semelhante ao da população residente, "[...] na região Norte encontram-se 31\% do total da população idosa, seguindo-se as regiões Centro e Lisboa, ambas com pesos próximos de 26\%. Nas regiões do Alentejo, Algarve, Autónomas da Madeira e dos Açores encontramse, respetivamente $9,1 \%, 4,4 \%, 2 \%$ e $1,6 \%$ dos idosos residentes no país".

Esse ritmo do envelhecimento leva à necessidade de mais respostas sociais, trazendo várias consequências e desafios. Torna-se fulcral que as instituições tenham condições de permitir um envelhecimento ativo, autônomo e digno aos nossos idosos.

O envelhecimento ativo é encarado como um "processo de otimização das oportunidades de saúde, participação e segurança, com o objetivo de melhorar a qualidade de vida à medida que as pessoas ficam mais velhas". ${ }^{2} \mathrm{O}$ projeto teve essa intenção, estimulando, ao mesmo tempo, o desenvolvimento educativo, cultural e social de cada idoso, sempre acompanhado de partilha de ideias, afetos e histórias de vida.

Acreditar que os idosos ao longo do seu processo de envelhecimento vão se tornando inúteis, tornando-se num entrave para o desenvolvimento da população, é um preconceito. Aliás, "tratar o envelhecimento como um problema social é um profundo desrespeito com aqueles que construíram e sustentaram uma sociedade, com seu poder de decisão e autonomia". ${ }^{3}$ A verdade é que, ao longo do processo de envelhecimento, ocorre "um conjunto de modificações morfológicas, fisiológicas, bioquímicas e psicológicas, que determinam a perda progressiva da capacidade de adaptação do indivíduo ao meio ambiente" ${ }^{" 4} \mathrm{e}$ "as capacidades de adaptação do ser humano vão diminuindo, tornando-o cada vez mais sensível ao meio ambiente que, consoante as restrições implícitas ao funcionamento do idoso, pode ser um elemento facilitador ou um obstáculo para a sua vida". ${ }^{5}$

Não se pode negar que essa população apresenta algumas fragilidades (as doenças surgem, ou se acentuam), perdendo algumas de suas faculdades motoras e cognitivas; além disso, essa faixa etária é confrontada com a alteração dos papéis profissionais e sociais, como a aposentadoria. É necessário entender que "[...] as pessoas idosas contribuíram para o desenvolvimento da sociedade, honraram seus compromissos, lidaram com as dificuldades inerentes ao ato de viver e, apesar de tudo, continuam a viver $[\ldots]^{\prime \prime 6}$ e, por vezes, esses esforços não são tidos em conta nessa nova fase da vida. De um momento para o outro, o então idoso se vê sem nada para fazer, é confrontado com a alteração do seu papel social no seio familiar, no trabalho, na sociedade, fazendo com que este se sinta inútil ${ }^{6}$ e um fardo na sociedade que integra, sendo descartado da sociedade que ajudou a edificar. Torna-se fulcral introduzir novos conceitos e maneiras diferentes de viver, para que a adaptação a essa nova realidade e fase de vida seja flexível e aprazível. A diminuição da atividade, ou até mesmo o sedentarismo dessas pessoas traz consigo algumas consequências que afetam o processo de envelhecimento. São elas, por exemplo, a redução da capacidade de concentração, coordenação e reação que, por sua vez, levam ao surgimento de processos de desvalorização, baixa autoestima, desmotivação, solidão e/ou isolamento. ${ }^{7}$ Assim, devemos atuar junto das instituições e das entidades políticas, como junto de toda a população, para mudar esse estado de coisas. 
A velhice não pode nem deve ser subvalorizada, pois os mais velhos têm sabedoria e experiência que os mais novos não têm; aliás, por mais tecnologia e melhores condições de vida que existam, atentar para a voz da sabedoria/experiência, das pessoas maiores, é também meio caminho andado para o sucesso de qualquer povo. ${ }^{8}$ Essa intervenção teve similarmente, como intenção, alertar os idosos para o fato que a aprendizagem que acontece ao longo de toda uma vida não estagna mas está presente em cada dia que se vive. Cada dia traz novas e ricas aprendizagens, que possibilitam ao indivíduo continuar a formar-se e a interessarse pelos assuntos que afetam sua vida pessoal e coletiva. Ora, "o acesso à educação é um agente de desenvolvimento, de conhecimento, de interação, de novas descobertas, experiências e vivências, princípios necessários à preservação e conservação de uma vida mais positiva, proveitosa e saudável".?

O envelhecimento ativo é entendido como um curso de vida, em que envelhecer não se inicia num ponto específico, mas "[...] corresponde antes a um processo que se estende ao longo de toda a vida e em que a história individual se constrói progressivamente e se materializa em resultados profundamente heterogêneos e idiossincráticos" ${ }^{10}$ Essa nova abordagem em torno do envelhecimento baseia-se "no reconhecimento dos direitos humanos das pessoas mais velhas e nos princípios de independência, participação, dignidade, assistência e auto-realização", apoiando, desse modo, a responsabilidade de as pessoas praticarem o exercício de sua participação em processos políticos, sociais e culturais, ou seja, em todos os aspetos da vida em sociedade. A velhice não deve ser encarada negativamente. O idoso tem uma história de vida à qual estão intrínsecas qualidades como: sabedoria, experiência e maturidade que, se forem potencializadas, podem levar a um envelhecimento com satisfação. Estar consciente de que envelhecer não é morrer torna-se fulcral na promoção para um envelhecimento ativo. O idoso não deve entregar sua vida a outrem, mas lutar por ela e fazer por ter um final de vida digno e feliz. A velhice é, também, uma fase de aprendizagem e crescimento.

O objetivo desta intervenção foi contribuir para o envelhecimento ativo dos utentes desenvolvendo harmoniosamente todas suas dimensões, visando sempre que os utentes fossem autônomos, participativos e ativos.

\section{ABORDAGEM METODOLÓGICA}

O projeto "Viver a (e para) aprender: promoção do envelhecimento ativo" incidiu sobre uma população maioritariamente envelhecida do conselho da Póvoa de Lanhoso, distrito de Braga, Portugal, que se dirige aos respetivos centros-dia/convívio de livre e espontânea vontade para ali passar algum tempo e conviver com outras pessoas. Esse projeto durou nove meses, iniciando-se a $1^{\circ}$ de outubro de 2012 e finalizando a 30 de junho de 2013. As atividades do projeto eram facultativas, e nele se observaram as normas éticas de acordo com a Declaração de Helsínquie, de 2013.

O público-alvo abrangido pelo projeto tem idades compreendidas entre 50 e 85 anos e que residiam nos respetivos locais onde se encontram sediados os centros-dia/convívio. O centro de convívio A contou 12 usuários: três do sexo masculino e nove do sexo feminino; e o centro de convívio B, com 13 usuários: oito do sexo feminino e cinco do sexo masculino. Alguns desses usuários (7), para além de usufruírem dos serviços dos respectivos centros-dia/ convívio, recorriam, igualmente, às atividades desenvolvidas pelos centros sociais e centro comunitário, que se encontram localizados nas freguesias vizinhas, num raio de 4 a $7 \mathrm{~km}$.

Em ambos os centros-dia/convívio, existiam pessoas dinâmicas e prontas a fazer coisas novas, mas um dos centros se destacou: os usuários do centro de convívio B mostraram-se mais dinâmicos e abertos a novas experiências. Pelo contrário, os usuários do outro centro de convívio revelaram-se mais passivos e gostavam de permanecer no seu canto, sendo, por vezes, 
resistentes à elaboração das atividades, mas com cuidado e incentivo acabaram por fazer e gostar do resultado final. A verdade é que cada usuário tinha uma história de vida que o moldou e marcou; desse modo, levamos em consideração as características e particularidades de cada um. $\mathrm{O}$ público-alvo era bastante distinto e apresentava distintas características.

Para um melhor conhecimento da realidade na qual se intervém, é preciso adotar uma metodologia que seja a mais adequada à investigação/ intervenção a realizar. O paradigma utilizado nessa intervenção foi o interpretativo-hermenêutico, baseado na relação entre investigador e realidade estudada, "na qual o conhecimento só se obtém através de um processo de compreensão dos fenômenos, que permite a inteligibilidade interior que está na base do conhecimento do mundo social e da ação". ${ }^{11}$ Esse paradigma centra-se na compreensão do que é particular e único e aceita que a realidade é dinâmica, múltipla e holista. ${ }^{11}$ Assim, "o investigador postula uma variabilidade das relações entre as formas de comportamento e os significados que os atores lhes atribuem através das suas interacções sociais", 12 pois comportamentos idênticos podem corresponder a significados distintos, dependendo da perspectiva que cada um tem daquilo que o rodeia.

Ora, em qualquer tipo de investigação/ intervenção, a metodologia a utilizar deve ir ao encontro das necessidades e interesses do público-alvo. Dessa forma, e para um melhor conhecimento da realidade envolvente e dentro do paradigma apresentado, a metodologia que melhor se encaixou nesse projeto de intervenção/ investigação foi a investigação-ação participativa. Trata-se de uma metodologia que integra, quer a investigação do ponto de vista tradicional, quer o trabalho de intervenção com a população. A utilização da investigação-ação participativa permite ter um conhecimento efetivo dos significados que os sujeitos atribuem à realidade que os envolve, promovendo a participação ativa de todos os intervenientes. ${ }^{13,14}$

A par do paradigma e metodologia utilizada, os métodos e técnicas que orientaram a intervenção aqui apresentada foram, essencialmente, de natureza qualitativa, sendo que a de tipo quantitativo foi também utilizada para uma singela análise estatística de dados sociodemográficos. A conciliação dessas duas abordagens permitiu nos aprofundarmos sobre o objeto de estudo, além de obter mais informação. Ora, os métodos e técnicas selecionados e utilizados ao longo desse projeto de investigação/intervenção diferenciaram-se e, ao mesmo tempo, complementaram-se ao longo de todo o projeto, de acordo com as diferentes necessidades metodológicas que foram surgindo. Esses foram se adaptando continuamente ao público-alvo, pelos seguintes métodos e técnicas: pesquisa bibliográfica, análise documental, observação direta e participante, entrevista, inquérito por questionário, conversas informais, diário de bordo, registo fotográfico e análise temática de conteúdo.

Os métodos e técnicas de caráter qualitativo possibilitaram a aquisição de várias ilações que permitiram uma intervenção holítica, já que a coleta de dados originava novas informações e esclarecia algumas ideias preconcebidas por parte do investigador-observador. Os dados dos inquéritos por questionário foram estatisticamente tratados e organizados, de modo a registrar e organizar informação de melhor forma.

As atividades do projeto aqui apresentadas subdividiram-se em cinco temas: informática, educação para a saúde, educação ambiental, intergeracionalidade, e momentos de lazer e aprendizagem. As atividades planeadas para trabalhar cada um dos temas apoiaram-se em diversos métodos e técnicas que auxiliaram todo o trabalho desenvolvido. As estratégias utilizadas foram: a animação como forma de cativar a atenção dos usuários, método expositivo, dinâmicas e discussão em grupo, exploração de conhecimentos dos usuários, jogo, círculos de estudo e visitas culturais. Todos os métodos e técnicas de educação/formação utilizados permitiram a troca de experiências, saberes e histórias de vida entre os diferentes usuários. Facultou, igualmente, a promoção da reflexão e do sentido crítico e a importância do saber ouvir. 
A verdade é que não existem métodos $\mathrm{e}$ técnicas perfeitas, mas enquanto profissionais, devemos saber optar pelas mais adequadas, potencializando no público-alvo suas capacidades e motivações, estimulando-os a ser cidadãos ativos nas comunidades de pertença.

\section{APRESENTAÇ̃O E DISCUSSÃO DO PROJETO DE INTERVENÇÂOO E DOS RESULTADOS}

\section{Apresentação do projeto de intervenção}

O trabalho de intervenção/investigação de um projeto envolve diferentes fases e diferentes procedimentos. Esse projeto de intervenção se baseou em quatro fases: a fase de integração, a fase de diagnóstico, a fase de implementação e a fase de avaliação, que foi transversal a todo o projeto.

A fase de integração envolveu conversas com os usuários, monitora, coordenador dos centrosdia/convívio e acompanhante de estágio; coleta de material bibliográfico sobre a instituição, bem como a aproximação aos usuários por meio da realização das atividades propostas pela instituição. $\mathrm{Na}$ primeira fase, começamos por rever alguma literatura para fundamentar nosso trabalho, o que se estendeu por toda a intervenção.

$\mathrm{Na}$ fase de diagnóstico, foram realizados questionários aos usuários, a fim de identificar seus interesses e o que é feito pelos (e para os) usuários, bem como aferir o que eles gostariam de fazer. Foi também realizada entrevista à monitora responsável pelas instituições em questão, com o mesmo objetivo dos questionários, mas obtendo outra perspectiva observacional. Realizamos também observações diretas e participantes.

$\mathrm{Na}$ fase de implementação, foram realizadas as diferentes atividades pensadas com os usuários, desenhadas a partir dos dados recolhidos nos questionários de avaliação diagnóstica. Durante essa fase, não nos circunscrevemos apenas a realizar as atividades delineadas, mas também apoiamos e colaboramos nas atividades propostas pela própria instituição. A implementação das atividades por nós delineadas foram acompanhadas por uma avaliação contínua, nomeadamente, por meio da aplicação de um questionário no final de cada atividade, aliado a conversas e observações.

Por fim, na fase de avaliação, foram aplicados inquérito por questionário ao público-alvo e entrevista com a monitora institucional, para averiguar como ajuizavam as atividades implementadas. Com isto realizou-se estudo final para apurar se realmente o projeto fora de encontro com os objetivos previamente definidos.

As atividades planeadas foram ao encontro do objetivo previamente delineado e visaram mudanças positivas na vida dos usuários que frequentam os centros-dia/convívio, tendo sempre em consideração seus interesses e necessidades. Para tal, delineamos um conjunto de atividades que fossem do agrado de todos e lhes transmitissem novas aprendizagens, considerando suas aptidões, histórias e/ou experiências de vida. As diferentes atividades implementadas apelaram sempre à criatividade e imaginação dos usuários, para que as aprendizagens pessoais e coletivas se realizassem.

Às atividades delineadas e realizadas estão subjacentes os temas mencionados, escolhidos em função dos três pilares do envelhecimento ativo: saúde, segurança e participação. ${ }^{2}$

\section{Informática}

Estamos numa época em que as novas tecnologias dominam o mundo e proporcionam novas oportunidades. Os mais velhos "[...] necessitam de um tempo maior e seguem um ritmo mais lento para aprender a manipular e assimilar os mecanismos de funcionamento desses artefatos, seja para o uso pessoal e cotidiano ou em atividade profissional". ${ }^{15}$

Ao longo dessa intervenção, verificou-se que os mais velhos ficavam admirados com o avanço 
que as coisas apresentam e pensavam que não seriam capazes de lidar com essas mudanças e novas tecnologias, achando curiosidade mas, ao mesmo tempo, sentindo receios das novas máquinas e softwares.

Dessa forma, e como a aprendizagem não se restringe a uma etapa de vida, essa atividade visou abrir os horizontes dos usuários, proporcionarlhes o contato com novas ferramentas e aprendizagens e consciencializá-los, ao mesmo tempo, de que não é por serem mais velhos que não têm capacidade de aprender e manusear um computador. Apesar da idade e das dificuldades que lhes foram apresentadas, eles - com força de vontade e entusiasmo - aprenderam.

Aliás, o uso da informática não está limitado a determinada idade, mas aberto a todos, tal como acontece com a aprendizagem. Algumas pessoas mais velhas (como os usuários do projeto de intervenção) consideram-se incapazes de aprender algo novo, mas enganam-se: eles são tão capazes quanto seus filhos e netos e foi essa a ideia que também se desmistificou.

\section{Educação para a Saúde}

A Conferência de Alma-Ata enfatiza que a saúde é um "estado de completo bem-estar físico, mental e social, e não simplesmente a ausência de doença ou enfermidade - é um direito humano fundamental"'.16

Tendo em conta essa definição, é importante focar que a educação para a saúde deve ocorrer em vários contextos e em diversos momentos da vida do indivíduo, para que este possa adquirir conhecimentos necessários para seu bem-estar e qualidade de vida. Salienta-se que a promoção da saúde do indivíduo deve partir da sua própria consciencialização: uma pessoa consciente dos perigos, de uma má postura em relação a sua saúde, por exemplo, lutará pela manutenção saudável e equilibrada de sua vida.
Se a promoção da saúde é essencial em todas as idades, ela se torna inquestionável na terceira e quarta idades, sendo fundamental para que se criem, nos idosos, hábitos de vida saudáveis, nomeadamente no que concerne a sua alimentação e exercício físico. Nesse sentido, as questões de saúde são para a população idosa uma de suas maiores preocupações, na medida em que, devido a idade e suas condições de saúde, têm a necessidade de ter mais cuidados.

\section{Educação Ambiental}

A preocupação com as questões ambientais é imperativa no mundo em que vivemos. Torna-se fulcral proteger o que é nosso e, consequentemente, a nós mesmos.

Encontramo-nos numa época em que se fala bastante da sustentabilidade ambiental e, sendo os idosos um número crescente no nosso país, é necessário alertá-los também para esse fato. Por vezes, os idosos descuidam-se dessas questões e é preciso alertá-los para a necessidade atual de consciência ecológica. A verdade é que se torna clara a necessidade de mudar o comportamento do homem em relação à natureza, de modo a promover a sustentabilidade e práticas ecológicas, fomentando igualmente a qualidade de vida dos cidadãos, bem como seu sentido crítico em relação à problemática ambiental.

\section{Momentos de Lazer e Aprendizagem}

As diversas atividades realizadas no âmbito deste tema visaram proporcionar diversas formas de lazer aos usuários por meio de exercícios mentais e/ou físicos, incluindo diversos jogos e trabalhos manuais, e mesmo atividades ou jogos sugeridos pelos próprios usuários. Com esse tipo de atividade, pretendeu-se que os idosos trabalhassem sua faceta artística por meio de pintura, moldagem, desenho, colagens, entre outros. Essa foi uma forma de cativar a 
participação dos usuários, estabelecendo diversas dinâmicas de grupo e jogos.

Os trabalhos manuais, para além de contribuírem para uma ocupação saudável dos tempos livres, podem contribuir para um envelhecimento ativo, uma vez que os estimula a serem criativos e imaginativos. A par de tudo isso, a expressão artística, bem como a realização de trabalhos manuais, trabalha o lado motor, o raciocínio, a criatividade e, principalmente, possibilita as relações interpessoais. Ora, "com esta animação estimulam-se o autoconhecimento, a interação entre a pessoa e o grupo e a dinâmica de grupo"?

A criatividade é sem dúvida um fator que apela à originalidade e, consequentemente, apela à participação dos usuários, permitindo a expressividade de cada um, bem como a troca de ideias, a ajuda e a aprendizagem mútua entre si.

\section{Interação Intergeracional}

As atividades de interação intergeracional tiveram como finalidade proporcionar momentos de aprendizagem mútua, de interação, troca de saberes e tradições entre jovens e usuários. Ao estimular atividades que propiciem o encontro intergeracional, está-se conscientizando os jovens a repensarem seus conceitos em relação à velhice e aos idosos, promovendo, por sua vez, a inclusão do idoso na vida social. ${ }^{17}$ A compreensão do termo "velhice" traz concepções negativas, às quais estão inerentes o sofrimento, a doença e a morte, e é nesse sentido que se deve atuar, pois tem-se que conscientizar os jovens de que os idosos são seres humanos que devem permanecer ativos, pois são detentores de ricos e diversos saberes e, além disso, ajudaram a edificar a sociedade que integram. É, pois, necessário alargar mentes e desconstruir conceitos errados sobre a velhice.

Nesse convívio entre gerações, ambas possuem conhecimentos diferentes que podem ser desconhecidos para outra geração e "a troca de saberes possibilita vivenciar diversos modos de pensar, de agir e de sentir, e assim, poder renovar as opiniões e visões acerca do mundo e das pessoas". ${ }^{18}$ Essa renovação e transformação de conhecimento ocorrem mutuamente e em um movimento constante de construção e desconstrução.

Tendo em conta que as crianças e jovens das respectivas freguesias têm seu calendário escolar, tentamos atrair os jovens para os centros-dia/ convívio no tempo de férias, nomeadamente, na Páscoa e no início das férias de verão, apelando ao voluntariado e à necessidade de passarem tempo com seus seniores. Os jovens com os quais trabalhamos foram o grupo de catequese e o grupo de escuteiros, mas ao longo da nossa intervenção iam algumas crianças e jovens acompanhando seus avós, os quais participavam ativamente nas atividades propostas e auxiliavam os mais velhos, quando necessário.

No quadro 1, podem se observar as atividades pensadas e delineadas para cada tema. É importante ressalvar que os recursos materiais necessários nessa intervenção foram sempre que possível material reutilizável, com fim de alertar para a importância de reutilizar os materiais, bem como para minimizar custos. 


\begin{tabular}{|c|c|c|}
\hline Temas & \multicolumn{2}{|l|}{ Atividades } \\
\hline \multicolumn{3}{|c|}{ "Aprender a teclar" } \\
\hline \multirow{5}{*}{ Educação para a saúde } & "Mezinhas do passado" & \multirow{7}{*}{$\begin{array}{c}\text { "Saúde, } \\
\text { ambiente } \\
\text { seus mitos } \\
\text { verdades" }\end{array}$} \\
\hline & $\begin{array}{c}\text { "A alimentação e a pirâmide } \\
\text { alimentar" }\end{array}$ & \\
\hline & "Dossiê de receitas saudáveis" & \\
\hline & "O exercício físico" & \\
\hline & "Workshop sobre primeiros-socorros" & \\
\hline \multirow{2}{*}{ Educação ambiental } & "Ponto verde" & \\
\hline & "A minha flor" & \\
\hline \multirow{6}{*}{ Momentos de lazer e aprendizagem } & \multicolumn{2}{|l|}{ "Moldura para fotografias" } \\
\hline & "Toca a mexer" & \\
\hline & "O jogo" & \\
\hline & "Visita aos presépios de Garfe" & \\
\hline & "O presépio" & \\
\hline & "O padroeiro" & \\
\hline Intergeracionalidade & \multicolumn{2}{|l|}{ "Troca de saberes" } \\
\hline
\end{tabular}

\section{Apresentação e discussão dos resultados}

A avaliação continuada ao longo de toda intervenção foi bastante importante para o sucesso e resultados satisfatórios que se obtiveram. Só dessa forma pudemos colmatar dificuldades e arranjar formas de cativar todos os usuários e não somente alguns. Ao longo da intervenção, fomos constatando algumas dificuldades que colmatamos e melhoramos com a sistemática avaliação que ia sendo feita, e considerando algumas sugestões e vontades explícitas dos diferentes usuários.

Todos os métodos e técnicas utilizadas na avaliação de todo o projeto foram fulcrais, mas o inquérito por questionário e a entrevista final aplicados permitiram recolher dados mais concretos sobre a opinião e perspectiva dos inquiridos sobre o trabalho desenvolvido e no qual eles tiveram papel bastante importante - aliás, o papel principal. O retorno foi imprescindível para identificar todo o desenvolvimento do projeto de intervenção e se os objetivos traçados foram cumpridos ou não.

Com base na análise dos questionários finais, foi percetível que os usuários gostaram do conjunto das atividades implementadas. Quando questionados se tinham gostado das atividades realizadas, todos eles responderam que sim, acrescentando que com elas aprenderam alguma coisa, mesmo que só fosse aprender a fazer algo de novo. Outros mencionaram ter gostado, particularmente, das atividades sobre a alimentação e da atividade "O padroeiro". Ainda quando questionados se houve alguma atividade de que gostassem menos, apenas uma senhora, do centro de convívio $B$, referiu que não apreciou tanto a atividade "O jogo".

Importa mencionar que atividade "Toca a mexer" não foi devidamente avaliada devido as alterações realizadas, mas por meio das conversas 
informais, constatou-se que os usuários gostaram, pois estavam se exercitando (sem se aperceberem) fazendo aquilo que mais gostam: jogar e dançar. E mesmo os que não saíam de suas cadeiras, através do ritmo da música, mexiam braços e pernas, lamentando não terem forças de dançar duas/três horas seguidas.

Uma de outras questões colocadas aos usuários foi: "Numa palavra, como avalia a totalidade das atividades realizadas?". Aqui todos os usuários usaram palavras positivas e animadoras para descrever as atividades. Os usuários do centro de convívio A descreveram a totalidade das atividades realizadas como sendo "boas", "educativas" e "jeitosas". E no centro de convívio B, as descreveram como "boas", "muito boas" e "educativas". O fato de os usuários terem considerado as atividades "boas" e "educativas" (porque aprenderam algo de novo) é um bom indicador do agrado dos usuários por esse projeto de intervenção, bem como do sucesso que o projeto teve junto ao público-alvo. Acima de tudo, a mensagem foi transmitida e os usuários foram conscientizados sobre os temas tratados, bem como tiveram oportunidade de ter contato com novas ferramentas e aprendizagens. Ora, os momentos de lazer dos usuários convertemse, também, em momentos de aprendizagem que faz dos usuários cidadãos mais ativos e participativos no grupo de trabalho, como na comunidade de pertença.

A ocupação dos tempos livres nessa faixa etária torna-se imprescindível para que essa fase não seja encarada negativamente e, dessa forma, esses momentos permitem a exploração de conhecimentos e "talentos" escondidos dos nossos seniores. A velhice é uma fase da vida que possibilita, igualmente, ao indivíduo, diversas aprendizagens que proporcionam seu crescimento e realização pessoal, portanto, a velhice não deve ser somente encarada como um tempo de descanso, mas, também, como um tempo de aprender. Dessa forma, o projeto teve sempre esse enfoque.

Nessa linha de pensamento, outra questão colocada aos usuários foi: "Com as atividades que realizou, ao longo destes nove meses, aprendeu alguma coisa de novo?", e a essa questão todos os usuários, à exceção de dois, afirmaram ter aprendido com as atividades desenvolvidas. Os usuários deram como exemplos de aprendizagens: fazer coisas novas com material reutilizável; ficaram a saber mais sobre a reciclagem; ficaram mais informados quanto à alimentação, isso no centro de convívio A. No centro de convívio B, eles afirmaram ter aprendido: a fazer coisas novas com material reutilizável; a ter uma alimentação equilibrada; aprenderam algumas mezinhas; aprenderam a reciclar; e aprenderam os cuidados que devem ter em casa. Outros mencionam que a forma como foram ajudados ao longo do projeto (realizado em 2013) foi uma aprendizagem. Os usuários de ambos os centros afirmam ter aprendido muitas mais coisas, estes são alguns exemplos.

Dessa forma, é de corroborar que os interesses e expectativas dos usuários foram respeitadas ao longo de toda a intervenção e, quando questionados sobre essa questão, todos, sem exceção, responderam positivamente.

No que se refere à avaliação feita pela monitora dos centros de dia/convívio, por meio da entrevista final, ela afirmou que o projeto implementado foi importante para a instituição, pois "as atividades implementadas foram diferentes e os temas tratados foram interessantes e importantes, bem como trouxe a possibilidade de eles trabalharem com o computador". Mencionou também que a vontade e os interesses dos usuários foram respeitados, afirmando: "eles gostavam do que estavam a fazer e isso é importante". Quanto às atividades, aquelas que ela mais destacou foram: no centro de convívio A, a atividade "aprender a teclar" e a atividade "o padroeiro"; e no centro de convívio $\mathrm{B}$, a atividade "a minha flor" e a atividade "o padroeiro". Numa avaliação geral a toda a intervenção, a monitora avaliou a intervenção como positiva e inovadora.

O projeto contribuiu para o desenvolvimento pessoal e social dos usuários, uma vez que eles se tornaram mais participativos e tinham sempre 
algo a dizer, trocando opiniões e ideias entre si. Eles fizeram coisas que não imaginariam fazer e que imaginavam não ser capazes, descobrindo, dessa forma, habilidades escondidas e aprendendo informações importantes para o decorrer da sua vida pessoal e coletiva. Ao longo das atividades, foram perceptíveis o entusiamo e as várias funcionalidades que os usuários iam dando ao objeto em construção e isto, sem dúvida, abriu-lhes a imaginação e os tornou mais ativos ao longo do projeto, desenvolvendo, ao mesmo tempo, suas capacidades cognitivas e artísticas. As sugestões e ideias partilhadas entre todos foram pontos essenciais no desenrolar de toda a intervenção, tanto e, particularmente, para o desenvolvimento de cada um, como para o sucesso da intervenção.

\section{CONSIDERAÇÕES FINAIS}

A realidade social em Portugal tem se agravado de modo bastante preocupante, sendo "[...] a ausência de uma política global e integral para a terceira idade foi uma constante [...]". ${ }^{19}$ As políticas públicas para a terceira idade são ainda muito precárias e quem lida diretamente com estes é que se apercebe das suas reais necessidades e do pouco interesse em investir em projetos para a terceira idade que os envolva ativa e diretamente. Dessa forma, e considerando os poucos recursos financeiros destinados a essa população, tornase preponderante pensar em infraestruturas adequadas para acolher o crescente número de idosos, bem como em atividades que façam deles pessoas mais ativas e dinâmicas.

O idoso, ao longo da sua vida, vai aprendendo, e durante esse processo de aprendizagem pode descobrir novas habilidades e talentos. Essa descoberta, no entanto, tem que partir de si e da sua vontade, como também de outros fatores extrínsecos ao indivíduo. A própria sociedade tem que criar possibilidades para que os idosos continuem a viver nesta nova fase da sua vida terceira e quarta idades - autonomamente, sendo ativos nas decisões sociais que cabem a todos e não somente a alguns. Os idosos, devido a sua experiência e seus saberes, são uma grande fonte de conhecimento e se tornam pedras basilares para o sucesso e crescimento da própria sociedade.

Qualquer projeto de investigação/intervenção tem seus altos e baixos e tem que ser flexível para qualquer possível mudança. O projeto "Viver a (e para aprender): promoção do envelhecimento ativo" foi alvo de algumas alterações ao que estava previamente previsto, para que as atividades fossem ao encontro das expectativas e interesses de todos e atingisse seu propósito com sucesso. É no decorrer da intervenção que se apercebem mais pormenorizadamente as dificuldades, necessidades e interesses do público-alvo. O projeto aqui apresentado levou em consideração a saúde, a participação e a segurança como princípios do envelhecimento ativo, seguindo as indicações da Organização Mundial da Saúde, de modo a conscientizar e capacitar os indivíduos de conhecimentos que os ajudassem a enfrentar seu quotidiano para participarem ativamente na sociedade.

Os resultados visíveis e satisfatórios obtidos com essa intervenção só vêm realçar a importância desse tipo de intervenções junto à população idosa. Torna-se bastante importante aproveitar esses espaços de convívio e lazer para (in)formar os idosos sobre a importância que eles assumem na comunidade que integram. É evidente que são necessários momentos de puro lazer, em que se partilhem vivências e haja interação entre os distintos indivíduos, mas as instituições também têm que lutar para fomentar em nossos seniores a vontade de participação ativa.

Todas as instituições, de tipo religioso ou estatal, têm que ter em conta os indivíduos como seres em constante aprendizagem. Por vezes, torna-se mais fácil proporcionar um conjunto de atividade que apenas os distraiam, mas é urgente que essas atividades tenham, igualmente, aprendizagens inerentes que ajudem os idosos a puxar pela imaginação no seu quotidiano comunitário. 


\section{REFERÊNCIAS}

1. Portugal. Instituto Nacional de Estatística. Mais de um milhão e duzentos mil idosos vivem sós ou em companhia de outros idosos [Internet]. Lisboa: INE; 2012 [acesso em 24 nov 2014]. Disponível em: http:// www.ine.pt/xportal/xmain?xpid=INE\&xpgid=ine_ destaques\&DESTAQUESdest_boui=134582847\&DE STAQUEStema $=55466 \& D E S T A Q U E S m o d o=2$

2. Organização Mundial de Saúde. Envelhecimento ativo: uma política de saúde [Internet]. Brasília, DF: Organização Pan-Americana de Saúde; 2005 [acesso em 09 dez 2012]. Disponível em: http://bvsms.saude. gov.br/bvs/publicacoes/envelhecimento_ativo.pdf

3. Jardim VCFS, Medeiros BF, Brito AM. Um olhar sobre o processo do envelhecimento: a percepção de idosos sobre a velhice. Rev Bras Geriatr Gerontol [Internet] 2006 [acesso em 08 nov 2013];9(2). Disponível em: http://revista.unati. uerj.br/scielo.php?script $=$ sci_arttext\&pid $=$ S1809$98232006000200003 \& \operatorname{lng}=$ pt\&nrm $=$ iso

4. Ferreira OGL, Maciel SC, Silva AO, Santos WS, Moreira MASP. O envelhecimento ativo sob o olhar de idosos funcionalmente independentes. Rev Esc Enferm USP [Internet] 2010 [acesso em 8 nov 2013];44(4):1065-69. Disponível em: http://www. scielo.br/pdf/reeusp/v44n4/30.pdf

5. Jacob L. Animação de idosos [Internet]. [S.l: s.n]; 2007 [acesso em 26 nov 2012]. Disponível em: http:// br.monografias.com/trabalhos-pdf/animacao-idosos/ animacao-idosos.pdf

6. Fonseca AM. O Envelhecimento: uma abordagem psicológica. Lisboa: Universidade Católica Editora; 2006.

7. Jacob L. Animação de idosos. Actividades. Porto: AMBAR; 2007.

8. Silvestre CA. Educação e formação de adultos e idosos: uma nova oportunidade. Lisboa: Instituto Piaget; 2013.

9. Ferraz CSC. Os idosos e o seu mundo: um projeto de animação [dissertação/relatório de estágio]. Braga: Universidade do Minho, Instituto de Educação; 2012 [acesso em 2013 jun 6]. Disponível em: https://repositorium.sdum.uminho.pt/ bitstream/1822/23788/1/Carla $\% 20$ Sofia $\% 20$ Carvalho\%20Ferraz.pdf
10. Ribeiro O, Paúl C. Manual de envelhecimento ativo. Lisboa: LIDEL; 2011.

11. Reis MP. Humanização da instituição hospitalar: contributo da prática voluntária [dissertação/ relatório de estágio]. Braga: Universidade do Minho, Instituto de Educação; 2010 [acesso em 06 mai 2013]. Disponível em: http://repositorium.sdum.uminho.pt/ bitstream/1822/15040/1/Mercedes $\% 20$ Peixoto $\% 20$ dos\%20Reis.pdf

12. Lessard-Hébert M, Goyette G, Boutin G. Investigação Qualitativa: fundamentos e práticas. Lisboa: Instituto Piaget; 2005.

13. Ander-Egg E. Repensando la Investigación-Acción Participativa. México: Editorial El Ateneo; 1990.

14. Erasmie T, Lima LC. Investigação e projectos de desenvolvimento em educação. Braga: Universidade do Minho, Unidade de Educação de Adultos; 1989.

15. Kachar V. Terceira idade e informática: aprender revelando potencialidades. São Paulo: Cortez; 2003.

16. World Health Organization. Declaration of Alma-Ata [Internet]. Alma-Ata, USSR: WHO; 1978 [acesso em 2013 jun 23]. Disponível em: http://www.who.int/ publications/almaata_declaration_en.pdf

17. Carvalho MCBNM. Relações Intergeracionais: alternativa para minimizar a exclusão social do idoso . Rev Portal Divulg [Internet] 2012 [acesso em 12 dez 2012];3(28):83-8. Disponível em: http:// portaldoenvelhecimento.org.br/revista-nova/index. $\mathrm{php} /$ revistaportal/article/view/321/321

18. Carvalho MCBNM. O diálogo intergeracional entre idosos e crianças: projeto "Era uma vez... atividades intergeracionais" [dissertação]. Rio de Janeiro: Pontifícia Universidade Católica do Rio de Janeiro; 2007 [acesso em 7 dez 2012]. Disponível em: http://www2.dbd.puc-rio.br/pergamum/ tesesabertas/0410376_07_cap_04.pdf

19. Veloso E. A análise da Política da Terceira Idade em Portugal, de 1976 a 2002 [Internet]. Lisboa: Faculdade de Ciências Sociais e Humanas; 2008 [acesso em 21 nov 2014]. Disponível em: http://www.aps.pt/ vicongresso/pdfs/412.pdf 